Article

\title{
An analysis of calorie consumption and elasticity in Vietnam
}

\author{
Linh Hoang $\mathrm{Vu}{ }^{1}$, 2,* \\ ${ }^{1}$ VNU Vietnam Japan University. Email: vhlinh76@gmail.com \\ ${ }^{2}$ Institute of Theoretical and Applied Research, Duy Tan University, Hanoi 100000, Vietnam
}

\begin{abstract}
This paper analyzes calorie consumption in Vietnam using the household survey data. The data suggest that food insecurity is still a major problem in Vietnam, with nearly 40 percent of the population being unable to meet their calorie requirement. Employing nonparametric and parametric estimation techniques, the paper examines the relationship between household calorie consumption and per capita household expenditure in Vietnam. The analysis indicates a positive and significant relationship between per capita expenditure and per capita calorie consumption. The mean calorie elasticity is estimated to be between 0.21 and 0.31 by the parametric method and 0.20 by non-parametric method. In addition, simulated income and food price changes indicate that undernutrition is very responsive to changes in income and food prices.
\end{abstract}

Keywords: Vietnam, food, calorie, elasticity.

\section{Introduction}

There have been two major strands of research on the relationship between nutritional status and economic status in developing countries. The first focuses on efficiency wages, initiated by Leibenstein (1957), and later expanded by Mirrlees (1975) and Stiglitz (1976). This literature argues that productivity, and thus wages, depends on nutritional status. According to this line of thought, wages cannot fall below beyond a certain point because workers need enough nutrition and food consumption to enable them to work effectively. This literature is primarily concerned with explaining unemployment in low-income countries.

A second strand of research postulates that nutrition, as measured by calorie consumption, is conditioned by income and by the demand for food. The demand for calories will rise with income; therefore, economic growth will help eliminate malnutrition. There have been many studies on the income elasticity (or expenditure elasticity) of calorie demand, but the empirical evidence is unclear. Subramanian and Deaton (1996), and Dawson and Tiffin (1998) estimated that the calorie-income elasticity for India was in 0.3 to 0.5 range. Sahn (1988) found income elasticities of calories ranging from 0.28 for low-income groups to 0.76 for high-income groups in Sri Lanka. Pitt (1983) estimated a calorieincome elasticity for Bangladesh of around 0.8. In contrast, Behrman and Deolalikar (1987) for India, Bouis and Haddad (1992) for the Philippines, and Ravallion (1990) for Indonesia have estimated calorieincome elasticities that are close to zero. If the calorie-income elasticities are insignificant or close to zero, economic growth may not be accompanied by an improvement in nutritional intakes.

In Vietnam, while there have been many studies addressing poverty reduction concerns, for example Minot and Baulch (2005), Baulch and Masset (2003), Vu \& Glewwe (2011), World Bank (2012), few studies 
have specifically addressed food security and nutrition aspects in this country. Molini (2006) describes the changes in food consumption patterns in Vietnam over time and finds evidence of substitution of low micronutrient food items, such as rice and cereals, and in favor of high micronutrient items, such as fruit, vegetables, fish and meat, during the 1990s. He also estimated the elasticity of calories with respect to expenditure for the years 1993 and 1998 and found a significant reduction in the calorie income elasticity over time, reflecting a general improvement in food security. Mishra and Ray (2006) examine changes in the prevalence of undernourishment (POU), as measured by the percentage of Vietnamese households unable to meet their daily minimum calorie requirements, from 1993 to 1998. They show that the prevalence of undernourishment in Vietnam was severe, with over 80 percent of Vietnam households undernourished in both years, as measured by calorie requirement standards established by the WHO. Trinh Thi et. al. (2018) use a method that of decomposition of between-year differences in economic outcomes into (1) the effect due to between-year change in the conditional distribution of the outcome given sociodemographic characteristics, or "structure effect", and (2) the effect due to the differences in sociodemographic characteristics across years, or "composition effect". The authors find that food expenditure and household size appear to be the main contributors to the composition effect. Meanwhile, urbanization and level of education are negatively related to the composition effect although these two variables effects are negligible compared to those of food expenditure and household size. Gibson \& Kim (2013) used household survey and market price data to estimate an eight-food demand system, allowing for both quality and quantity responses to price changes. The results suggest that, ceteris paribus, a ten percent increase in the relative price of rice reduces household calorie consumption by less than two percent, taking into account both quantity and quality substitution. The authors claimed that this elasticity would be wrongly estimated to be more than twice as large if quality substitution is ignored.

This paper adds to this body of evidence by examining food security and nutrition in Vietnam. Using the 2006 Vietnam Household Living Standard Survey (VHLSS) data, it estimates the expenditure elasticity of calorie demand, using both parametric and non-parametric approaches. It also analyzes the response of calorie intakes to simulated income and food price changes.

The remainder of the paper is structured as follows. Section 2 discusses data and methodology. Section 3 discusses empirical results. Finally, Section 4 provides the conclusion.

\section{Data and methodology}

\section{Data}

The 2006 VHLSS was conducted by Vietnam's General Statistics Office to collect data on household living standards, including data on household expenditure, income, and information on household members' occupations, health and education status. The survey was conducted nationwide. Expenditure and food consumption data were collected from 9,189 households in the 2006 survey. Information on food consumption expenditures were obtained for both regular and holiday expenses. The data were collected for both purchased goods and self-supplied food (home production). Data on food expenditures were collected for 56 food items.

For this study, the data on food consumption are aggregated into ten at-home food groups, and a food away from home group (FAFH) item. All food consumption is transformed into calories based on the calorie conversion table used by General Statistics Office of Vietnam to calculate the food poverty line. This conversion table was constructed by Vietnam's National Institute of Nutrition. The Vietnamese food composition table in this study differs from that used in Molini (2006) and Mishra and Ray (2006), who use the FAO's food composition table for international use (which was first published in 1949) to obtain calorie consumption. The calorie conversion table used in this study should reflect better calorie consumption in Vietnam because it was based on Vietnamese diets while the FAO table was constructed 
based on the most common food items consumed around the world. Thus, the FAO table may not reflect actual food consumption in a particular country.

For certain food items, VHLSS data were collected on value only, not on quantity. For these items, the average price of calories was calculated for the food items having quantity information. This price is then used to derive the equivalent calorie consumption from the food items without quantity data in the same food group, based on the value data. For example, the "other vegetables" have no quantity information. I calculated the average calorie price for "vegetables", based on those items in "vegetables" group having quantity data, such as beans, peas, and morning glory. Then, the approximated calories from "other vegetables" item was derived, using the expenditure for "other vegetables" item and the average price of "vegetables" group. For FAFH, I use the average price of calories for each household from all ten food categories consumed at home. Thus, it is assumed that consumers pay the same price for one calorie consumed at home and away from home.

\section{Methodology to estimate calorie consumption elasticity}

The impact of income (or expenditure) on calorie consumption is estimated using an econometric model of consumer demand. Calorie consumption is typically modeled as a function of several variables.

First, household per capita expenditure is expected to have a positive impact on per capita calorie consumption because as income increases, households normally spend more on food.

Second, the prices of food categories affect calorie consumption by both income effects (reducing real income as price increases) and substitution effects (substitute one food item for another as food prices change). In Vietnam, as in many other developing countries, food prices are typically higher in urban areas than in rural areas, which may affect calorie consumption.

Third, certain household characteristics can affect calorie consumption. Household composition affects food choices, and therefore, calorie consumption. For instance, adults tend to consume more calories than children and males more than females. Household size also influences calorie consumption. Economies of scale in food buying, storing, and preparing within the household will permit more consumption of food per household member and therefore more calorie consumption per capita in larger households. On the other hand, in larger households, children are a larger share of household members, and children eat less than adults, so food expenditure per capita may decrease as household size increases, resulting in a possible negative relationship between calorie consumption per capita and household size.

Another important determinant of household per capita calorie consumption is education. The impact of education on calorie consumption is not always clear. Better-educated adults are more aware of nutrition demand, thus may want to adjust their calorie consumption to meet the recommended calorie intakes. In developing countries where a large percentage of the population is undernourished, this often means an increase in calorie intakes. But better-educated adults may need less energy than less-educated adults because they are less likely to engage in manual work. Better-educated households might also put more "weight" on food quality, convenience and taste than do less-educated households. Thus, better education might enable households to substitute foods rich in calories with foods with higher quality or better taste. In this paper, I use two measures of education: head's schooling years and the average years of schooling from adult women in the family.

While household heads are important as the likely decision-maker in the family, it is often the women who prepare meals for the family. Therefore, women's schooling may play an important factor in determining food consumption, and thus the calorie consumption per capita, of household members. 
Other relevant household characteristics include the number of household members working in agriculture, and the dummy variables that indicate whether the household lives in an urban area or belongs to an ethnic minority. Farming often requires more calorie consumption than non-farm work. Food availability and eating habits may differ between the urban and the rural areas and between the ethnic majority and the ethnic minorities. Finally, some dummy variables such as geographical regions and seasonality are included to capture unobserved geographic and seasonal differences.

The following functional form is employed to estimate the expenditure elasticity of calorie:

$$
\ln C_{i}=\beta_{1 i} \ln X_{i}+\beta_{2 i}(\ln X)^{2}+\Sigma_{\mathrm{j}} \theta_{i j} \ln p_{i j}+\Sigma_{\mathrm{k}} \gamma_{i k} Z_{i k}+\alpha_{i}+\epsilon_{i}
$$

and the expenditure elasticity of food consumption:

$$
\ln F_{i}=\beta_{1 i} \ln X_{i}+\beta_{2 i}(\ln X)^{2}+\Sigma_{\mathrm{j}} \theta_{i j} \ln p_{i j}+\Sigma_{\mathrm{k}} \gamma_{i k} Z_{i k}+\alpha_{i}+\epsilon_{i}
$$

where $\underline{C_{i}}$ is per capita calorie consumption of household $i ; F_{\mathrm{i}}$ is per capita food consumption; $X_{i}$ is per capita expenditure (PCE); $p_{i}$ is a vector of prices of food groups; $Z_{i}$ is a vector of household characteristics; and $\epsilon_{i}$ is the error terms. Both $\ln X$ and $(\ln X)^{2}$ are used to a capture possible non-linear relationship between expenditure and calorie consumption. Similar to Ravallion (1990), average unit values of food groups within each of the cluster (commune in this paper) are used for the prices in $p_{i}$.

The vector $Z_{i}$ includes household head's age, years of schooling of the household head; average years of schooling of adult women (> 15 years); household size; the proportions of household members who are infants ( $<3$ years), children (3-15 years) and adults ( $>59$ years); number of household members engaged in agriculture; and dummy variables for urban households, ethnic minorities, regions, and seasonality.

\section{Findings}

Table 1 presents the mean prices of purchasing 1,000 calories for each food category. As expected, rice provides calories at the lowest cost, followed by other staples. On the other hand, poultry and other meats (mainly beef) are the most expensive in terms of calorie content. On average, a household in the richest quintile pays almost triple the amount paid by a household in the poorest quintile for a given amount of calorie consumption. This reflects the fact that poorer households consume higher shares of foods that provide calories at a low cost, such as rice and other food staples, than do richer households. In addition, as seen in Table 1, poorer households also consume lower-quality items within all food categories. Therefore, the calorie prices paid by poorer households are lower than those paid by richer households. The gaps between calorie prices paid by poorer and richer households are most notable for those food items that richer households consume more frequently, such as FAFH, fruits, other foods and fish. This implies that, for these food items, richer households pay more for food attributes other than calorie content, such as quality, taste, and vitamins. It is calculated that, on average, a household in the top income quintile pays almost 5,800 VND for 1,000 calories while a household in the bottom quintile pays just 2,000 VND for the same quantity of calories. In a similar manner, on average, an urban household pays 5,160 VND per 1,000 calories while a rural household only pays 2,880 VND.

Table 1: Average Price of 1000 Calories, by Type of Food (thousands VND), 2006.

\begin{tabular}{ccccc}
\hline Mean & Bottom 20\% & Top 20\% & Rural & Urban \\
\hline
\end{tabular}




\begin{tabular}{lrrrrr}
\hline Rice & 0.35 & 0.28 & 0.46 & 0.33 & 0.41 \\
Other staples & 0.66 & 0.49 & 0.84 & 0.63 & 0.74 \\
Pork & 2.32 & 1.79 & 2.95 & 2.22 & 2.64 \\
Other meats & 13.99 & 8.90 & 17.55 & 12.85 & 16.22 \\
Poultry & 11.85 & 9.68 & 14.85 & 11.27 & 13.65 \\
Fish & 7.28 & 4.85 & 11.59 & 6.27 & 10.27 \\
Vegetables & 2.12 & 1.59 & 2.89 & 1.92 & 2.70 \\
Fruits & 3.35 & 1.93 & 5.33 & 2.85 & 4.70 \\
Other foods & 3.64 & 1.99 & 6.38 & 3.06 & 5.38 \\
Drink & 0.96 & 0.75 & 1.44 & 0.86 & 1.24 \\
FAFH & 1.07 & 0.49 & 2.14 & 0.83 & 1.76 \\
\hline
\end{tabular}

Table 2 presents total per capita calorie consumption and the percentage of calorie consumption from different food sources in Vietnam in 2006. To save space, only information for the poorest and the riches quintiles are reported in Table 2. Rice is the main calorie source for most households, providing 59 percent of total calorie consumption, and accounting for 26 percent of food expenditure. It is the primary food in the diets of all Vietnamese, regardless of sector, income or region. The importance of rice and staple foods declines as household incomes increase. In the top income quintile, rice and staples provide 59 percent of calorie consumption. Rice and other staple foods provide 77 percent of calorie consumption for the households in the lowest expenditure quintile. Other commodity groups have smaller shares of total household calorie consumption. The category 'Other foods' includes items such as fats and oils, eggs, milk (except fresh milk), which contributes nearly 10 percent of calorie consumption. Food away from home (FAFH) comprises nearly 8 percent of calorie consumption.

Table 2: Shares of Calorie Availability, Dietary Diversity, and Quantity Consumed

\begin{tabular}{|c|c|c|c|c|c|c|c|c|c|c|c|}
\hline & Rice & $\begin{array}{c}\text { Stapl } \\
\text { es }\end{array}$ & Pork & $\begin{array}{l}\text { Other } \\
\text { meats }\end{array}$ & $\begin{array}{c}\text { Poul } \\
\text { try }\end{array}$ & Fish & $\begin{array}{c}\text { Vegeta } \\
\text { bles }\end{array}$ & Fruit & $\begin{array}{c}\text { Drin } \\
k\end{array}$ & $\begin{array}{l}\text { Other } \\
\text { foods }\end{array}$ & FAFH \\
\hline \multicolumn{12}{|c|}{ Shares of calories (\%) } \\
\hline All & 59.0 & 5.0 & 5.4 & 0.3 & 0.9 & 2.1 & 4.4 & 3.3 & 1.7 & 9.9 & 7.8 \\
\hline Rural & 62.5 & 4.8 & 4.9 & 0.3 & 0.9 & 2.0 & 4.4 & 3.3 & 1.6 & 9.2 & 6.1 \\
\hline Urban & 48.5 & 5.6 & 7.0 & 0.6 & 1.0 & 2.4 & 4.5 & 3.3 & 2.0 & 12 & 12.9 \\
\hline Lowest 20\% & 71.3 & 5.5 & 3.1 & 0.1 & 0.6 & 1.5 & 4.7 & 2.5 & 1.2 & 6.7 & 2.5 \\
\hline Highest $20 \%$ & 44.1 & 6.0 & 7.8 & 0.8 & 1.3 & 2.4 & 4.7 & 3.9 & 2.4 & 12.7 & 13.8 \\
\hline \multicolumn{12}{|c|}{ Shares of food expenditures (\%) } \\
\hline All & 26.4 & 2.9 & 13.1 & 5.6 & 2.9 & 9.9 & 6.7 & 3.4 & 4.9 & 14.5 & 9.6 \\
\hline Rural & 29.6 & 3.0 & 13.1 & 6.0 & 2.4 & 9.6 & 6.8 & 3.2 & 4.6 & 14.4 & 7.3 \\
\hline Urban & 16.9 & 2.6 & 13.1 & 4.5 & 4.5 & 10.8 & 6.4 & 4.1 & 5.7 & 15.0 & 16.4 \\
\hline Lowest $20 \%$ & 41.4 & 3.3 & 10.5 & 5.7 & 1.5 & 8.4 & 7.3 & 2.5 & 3.5 & 13.3 & 2.7 \\
\hline Highest $20 \%$ & 13.7 & 2.7 & 13.6 & 5.1 & 5.1 & 9.8 & 5.9 & 4.6 & 6.8 & 14.9 & 18 \\
\hline \multicolumn{12}{|c|}{ Quantities consumed (per capita/year, in kg except in liter for drink) } \\
\hline All & 140.2 & 17.1 & 12.9 & 1.0 & 4.9 & 16.7 & 38.2 & 11.3 & 15.6 & 49.0 & $\mathrm{n} / \mathrm{a}$ \\
\hline Rural & 150 & 17.1 & 11.9 & 0.6 & 4.8 & 16 & 36.3 & 10.2 & 13.2 & 45.8 & $\mathrm{n} / \mathrm{a}$ \\
\hline Urban & 110.7 & 16.9 & 15.9 & 2.1 & 5.0 & 18.8 & 44 & 14.5 & 22.5 & 58.6 & $\mathrm{n} / \mathrm{a}$ \\
\hline Lowest 20\% & 145.3 & 18.5 & 6.2 & 0.2 & 2.7 & 9.5 & 23.5 & 6.0 & 6.9 & 28.0 & $\mathrm{n} / \mathrm{a}$ \\
\hline
\end{tabular}




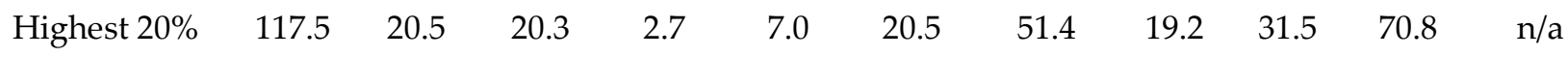

The budget shares of high quality protein-rich foods (meats, milk, eggs, oil, fish etc.) and timesaving, convenience foods (FAFH) increase as income increases. For example, the budget share of meat and fish of households in the highest expenditure quintile is more than twice the corresponding figures in the poorest quintile. In terms of quantity, the quantity of meat and fish consumed among the highest expenditure quintile is $51 \mathrm{~kg}$ per capita per year, while that among the lowest expenditure quintile is 19 $\mathrm{kg}$ per capita per year. Similarly, the budget share of FAFH in the top-income quintile is more than five times that of the poorest quintile. In addition, protein-rich and time-saving foods have higher expenditure shares in urban areas than in rural areas. Meat and fish contribute 8 percent of calorie consumption in rural areas but 11 percent in urban areas. The FAFH share of calorie consumption is only 6 percent in rural areas but 13 percent in urban areas.

Except for rice and staples, all foods are consumed in larger quantities by households in the higher expenditure groups. For rice, the lowest-expenditure group consumes less than the lower-middle expenditure (quintile 2) and the middle-expenditure (quintile 3) groups but higher than the upper-middle (quintile 4) and the highest expenditure (quintile 5) groups. This indicates that when their incomes increase, households increase their rice consumption. However, when their income reaches a certain level, households substitute rice with other foods, resulting in a reduction in the consumption of rice. In contrast, the consumption of other staples at first reduces from quintile 1 to quintile 2 but then increases as income increases. It is possible that households in the lowest-expenditure group consume large amount of low cost staple foods such as corn/maize, cassava, and sweet potatoes, which are less expensive in terms of price per calorie than rice. When their income increases, they substitute such staple foods with rice. However, as their income continues to rise, they might increase their consumption of staples such as wheat, noodles, rice noodles, and wheat, which are more expensive than rice.

Dietary diversity is often considered an important measure of household food security. A study by Hoddinott and Yohannes (2002) of 10 developing countries showed a strong positive association between household-level dietary diversity and food energy availability. The authors suggested that dietary diversity could be a useful measure for food security, especially if obtaining detailed data on food security status is time consuming and expensive. Arimond and Ruel (2004) examined data from 11 demographic and health surveys and found that dietary diversity is positively associated with child nutritional status, in particular with children's height-for-age Z-scores.

Table 2 demonstrates that richer households consume more diversified diets than poorer households, including much higher shares of such foods as meat, fish, fruits, all of which are important sources of protein, vitamins, calcium, iron and other micronutrients. Specifically, household dietary diversity can be measured by the Simpson index. This index of food diversification can be written as: $\mathrm{I}=1$ $\sum w_{i}{ }^{2}$ in which $w_{i}$ is the calorie share of food $i$. A high Simpson index, which in the range 0 to 1 , reflects a more diversified diet. We find that the Simpson index of richer households is much higher than it is for poorer households. The Simpson index of the households in the bottom quintile is 0.44 , while that of those in the top quintile is 0.71 . As expected, urban households consume more diversified diets than rural households. The Simpson index of urban households is 0.68 , compared with 0.55 of rural households. The total per capita calorie availability among Vietnamese households is estimated to be 2348 calories/per day. Rural households have higher calorie intakes than urban households, as found by previous studies of Vietnam and other developing countries (for example Molini 2006 for Vietnam, Ray 2007 for Vietnam and India, and Sahn 1988 for Sri Lanka).

Several previous studies have pointed out the divergence between Vietnam's record on poverty reduction and its record on malnutrition. Baulch and Masset (2003) argued that monetary poverty, i.e. 
poverty measured in terms of money values, is less persistent than either malnutrition among adults (measured by Body Mass Index) or stunting among children in Vietnam in the 1990s. They claimed that defining chronic poverty based on either monetary poverty or on malnutrition can lead to significantly different results. Chronic poverty is much more severe when measured by malnutrition than when measured by monetary poverty. Mishra and Ray (2006) pointed out that malnourishment was very prevalent in Vietnam throughout the 1990s, and there was no progress in reducing malnutrition in the 1990s regardless of achievements in reducing monetary poverty. Based on the WHO criteria of minimum calorie requirements, they estimated that 82 percent and 86 percent of Vietnamese households were undernourished in 1992/93 and 1997/98, respectively.

Based on the estimates of calorie consumption presented above, this study calculates the incidence of undernutrition, using the nutrition threshold of 2100 calories/day. Households are defined as undernourished if their per capita calorie availability is less than 2,100 calories/day in 2006. Table 3 presents the undernutrition and poverty situation in Vietnam. The poverty line used is the national poverty line, set by General Statistics Office of Vietnam of 2,559.85 thousand VND per year or around 213 thousand VND per month (equivalent to $\$ 13 /$ month at the nominal exchange rate in 2006). The poverty (undernutrition) headcount is simply the percentage of households living under the poverty (undernutrition) line. The poverty (undernutrition) gap is the normalized shortfall of households with real per capita expenditure (calorie intake) below the poverty (undernutrition) line, expressed in proportion to the poverty (undernutrition) line.

Mathematically, these indices are calculated as (Foster, Greer and Thorbecke 1984):

$$
\begin{aligned}
\mathrm{P}(\alpha) & =\sum \mathrm{p}\left(\mathrm{k}_{\mathrm{i}}, \mathrm{z}\right)=\left(1-\mathrm{k}_{\mathrm{i}} / \mathrm{z}\right)^{\alpha}(\alpha \geq 0) \text { for } \mathrm{k}_{\mathrm{i}}<\mathrm{z} \\
& =0 \text { otherwise, }
\end{aligned}
$$

where $k_{i}$ is the real per capita expenditure (or calorie intake) of household $i$ and $\mathrm{z}$ is the poverty line (or undernutrition line). When $\alpha=0$, one has the poverty (or undernutrition) headcount index $\mathrm{P}(1)$; when $\alpha$ $=1$, one obtains the poverty (or undernutrition) gap $\mathrm{P}(2)$.

Table 3 indicates that undernutrition is prevalent among Vietnamese households, even though less than 16 percent of Vietnamese households are classified poor in monetary terms. Almost 38 percent of households in Vietnam, 36 percent in rural areas and 45 percent in urban areas are undernourished. On average, rural households have higher (monetary) poverty rates and lower income but have lower undernourishment rates and higher calorie consumption than urban households. Even among the richest quintile, 29 percent of the households have lower calorie consumption than the minimum requirements.

Table 3: Undernutrition and Poverty Indices

\begin{tabular}{lcccc}
\hline & $\begin{array}{c}\text { Undernutrition } \\
\text { headcount }\end{array}$ & $\begin{array}{c}\text { Undernutrition } \\
\text { gap }\end{array}$ & $\begin{array}{c}\text { Poverty } \\
\text { headcount }\end{array}$ & $\begin{array}{c}\text { Poverty } \\
\text { gap }\end{array}$ \\
\hline All & 38.1 & 6.2 & 15.5 & 3.7 \\
Rural & 36.0 & 5.7 & 19.5 & 4.7 \\
Urban & 44.6 & 7.9 & 3.4 & 0.6 \\
\hline Red River Delta & 36.2 & 5.4 & 8.8 & 1.5 \\
North East & 28.9 & 4.2 & 23.2 & 5.2 \\
North West & 43.3 & 6.3 & 50.4 & 16.6 \\
North Central Coast & 46.5 & 7.6 & 24.2 & 5.9 \\
South Central Coast & 46.7 & 7.7 & 10.7 & 2.2 \\
Central Highlands & 42.0 & 7.6 & 24.6 & 6.7 \\
South East & 44.1 & 8.4 & 6.4 & 1.7
\end{tabular}




\begin{tabular}{lcccc} 
Mekong River Delta & 32.0 & 5.4 & 9.4 & 1.7 \\
\hline Quintile 1 & 60.6 & 11.0 & 79.1 & 18.8 \\
Quintile 2 & 40.3 & 6.0 & 0.0 & 0.0 \\
Quintile 3 & 31.8 & 4.8 & 0.0 & 0.0 \\
Quintile 4 & 30.1 & 4.7 & 0.0 & 0.0 \\
Quintile 5 & 28.6 & 4.9 & 0.0 & 0.0 \\
\hline Non-poor & 33.4 & 5.2 & 0.0 & 0.0 \\
Poor & 63.9 & 12.1 & 100 & 23.7 \\
\hline Ethnic majority & 38.4 & 6.3 & 9.5 & 1.8 \\
Ethnic minorities & 36.9 & 5.9 & 49.2 & 14.1 \\
\hline Non-farmer & 47.0 & 8.8 & 5.3 & 1.1 \\
Farmer & 34.7 & 5.3 & 19.5 & 4.7 \\
\hline
\end{tabular}

Table 3 shows that undernutrition is less severe in rural areas than in urban areas, even though the average rural household typically has a lower income than the average urban household. Perhaps working in rural areas, which often involves manual farm work, requires more energy and thus more calories than in urban areas. Studies of Vietnam by Mishra and Ray (2006) and Molini (2007) found that the average calorie consumption of the urban population is significantly lower than that of rural population. Studies of other countries, such as Skoufias (2003) for Indonesia, Ray (2007) for India, and Sahn (1988) for Sri Lanka, also found that the rural populations consumed more calories per capita than urban populations.

Two models are estimated for (2) and (3). The first (OLS1) excludes commune fixed effects, while the second includes commune fixed effects to control for possible unobserved community influences on eating patterns. In the latter (OLS2), the price variables, geographic variables and urban variable are omitted because these variables do not vary within communes. The regression results are presented in Table 5, with the coefficients of regions and seasonality omitted. The White Correction for robust standard errors is used to correct for heteroskedasticity.

In both models, the log of PCE variable has a positive and significant effect on calorie consumption while the log of PCE squared variable has a negative and significant effect. The mean expenditure elasticity of calorie intake is estimated to be 0.25 in the model without communed fixed effects and 0.22 in the model with commune fixed effects. To my knowledge, only one previous study (Molini 2007) has estimated calorie elasticities for Vietnam. The income elasticities of calories are estimated by Molini (2007) to be 0.36 in 1993 and 0.25 in 1998, the latter of which is similar to these estimates for 2006.

In the model without community fixed effects, the prices of other staples, pork, other meats, poultry, other foods and drink have negative and significant effects on calorie intake. The price of pork has the largest negative impacts on calorie demand, followed by the price of staples. On the other hand, the price of vegetables has a positive effect on calorie intake, possibly because households shift to more calorie-rich foods such as rice and other staples when the price of vegetables increases. The impact of rice prices on calorie intakes is positive. At first glance, this result seems puzzling because rice is the largest component of the diet for most Vietnamese households, providing about 60 percent of calories, and one might expect that an increase in the price of rice would lead to a decrease in total calorie intake. However, over 50 percent of the households in the 2006 VHLSS sample grew rice, and most of these farmers were net rice sellers. Thus, rice prices increase may have a positive "income-effect" among rural households, such that they increase their overall calorie consumption. This income effect may compensate the negative effect of the price of rice on calorie intake. 
When separate regressions are estimated for urban and rural households, the impact of rice prices on the calorie intakes is positive and significant among rural households and negative and insignificant among urban households. To further investigate this aspect, I estimate separate regressions with dependent variables being logarithms of calories from 11 food categories. In rural areas, increases in the prices of rice lead to higher calorie consumption from pork, vegetables, and 'other foods', and have no significant impact on calorie consumption from all other food categories. In urban areas, increases in the prices of rice lead to lower calorie consumption from rice, higher calorie consumption from vegetables, other meats, and drinks and have no significant impacts on calorie consumption from other food categories.

In short, it appears that rice price increases lead to increases in the calorie consumption of rural households, while they have a negative but insignificant impact on calorie consumption of urban households. Since about 75 percent of households in our sample are from rural areas, the overall impact of an increase in the price of rice on household energy availability is positive.

Table 4: Regressions of Calorie Per Capita and Food Consumption Per Capita

\begin{tabular}{|c|c|c|c|c|c|c|c|c|}
\hline & \multicolumn{4}{|c|}{ Calorie equation } & \multicolumn{4}{|c|}{ Food expenditure equation } \\
\hline & \multicolumn{2}{|c|}{ OLS1a } & \multicolumn{2}{|c|}{ OLS2a } & \multicolumn{2}{|c|}{ OLS1b } & \multicolumn{2}{|c|}{ OLS2b } \\
\hline & Coeff. & t-stat & Coeff. & t-stat & Coeff. & t-stat & Coeff. & t-stat \\
\hline Log of PCE & 0.91 & 10.08 & 1.02 & 8.56 & 1.54 & 14.75 & 1.72 & 14.27 \\
\hline Log of PCE squared & -0.04 & -7.39 & -0.05 & -6.76 & -0.05 & -8.54 & -0.07 & -9.47 \\
\hline Prices of & & & & & & & & \\
\hline Rice (log) & 0.03 & 2.41 & & & 0.07 & 5.89 & & \\
\hline Staples (log) & -0.04 & -6.81 & & & 0.00 & 0.75 & & \\
\hline Pork (log) & -0.13 & -7.77 & & & 0.10 & 5.76 & & \\
\hline Other meats (log) & -0.03 & -3.64 & & & 0.00 & 0.19 & & \\
\hline Poultry (log) & -0.02 & -3.6 & & & -0.02 & -2.76 & & \\
\hline Fish (log) & -0.03 & -3.94 & & & 0.04 & 5.31 & & \\
\hline Vegetables (log) & 0.00 & 0.65 & & & -0.01 & -1.12 & & \\
\hline Fruit (log) & -0.02 & -5.81 & & & 0.02 & 4.18 & & \\
\hline Other foods (log) & -0.01 & -2.65 & & & 0.01 & 2.80 & & \\
\hline Drink (log) & -0.04 & -7.05 & & & -0.01 & -2.55 & & \\
\hline FAFH $(\log )$ & 0.03 & 0.72 & & & 0.36 & 7.92 & & \\
\hline Head's age (log) & 0.02 & 1.31 & 0.04 & 2.5 & -0.03 & -2.00 & -0.02 & -1.33 \\
\hline Household size (log) & -0.10 & -12.1 & -0.11 & -12.6 & -0.11 & -13.3 & -0.14 & -14.5 \\
\hline Head's schooling (log) & -0.01 & -1.88 & -0.01 & -1.86 & 0.01 & 1.07 & 0.01 & 1.01 \\
\hline Women's schooling (log) & -0.04 & -6.97 & -0.01 & -2.24 & -0.03 & -6.93 & -0.01 & -1.67 \\
\hline Female head & -0.03 & -4.61 & -0.02 & -2.93 & -0.02 & -3.27 & -0.02 & -2.58 \\
\hline Urban & -0.04 & -4.67 & & & 0.05 & 5.83 & & \\
\hline Minority & 0.09 & 9.45 & 0.06 & 3.05 & 0.06 & 6.38 & 0.00 & 0.27 \\
\hline Infant proportion & -0.34 & -11.5 & -0.38 & -11.7 & 0.03 & 1.09 & -0.02 & -0.67 \\
\hline Children proportion & -0.05 & -3.18 & -0.07 & -4.05 & 0.00 & 0.25 & -0.01 & -0.79 \\
\hline Elderly proportion & -0.10 & -7.38 & -0.13 & -8.26 & -0.02 & -1.50 & -0.04 & -2.56 \\
\hline Female proportion & -0.03 & -2.15 & -0.05 & -3.23 & -0.06 & -4.24 & -0.08 & -4.85 \\
\hline
\end{tabular}




\begin{tabular}{lrrrrrrrr} 
Farming members & 0.10 & 13.16 & 0.08 & 7.36 & 0.01 & 4.77 & 0.01 & 4.68 \\
Constant & 3.84 & 9.76 & 2.54 & 4.96 & -1.92 & -4.33 & -1.56 & -3.06 \\
\hline R-square & 0.30 & & 0.65 & & 0.77 & & 0.89 &
\end{tabular}

Note: Shading areas implies significant at 5 percent.

Household size has a significant negative effect on calorie intake per capita, indicating that larger households tend to consume lower calorie intake per capita than smaller households. This is observed in most calorie elasticity studies, such as in Molini (2007) for Vietnam, Gibson and Rozelle (2002) for Papua New Guinea, and Abdulai and Aubert (2004a) for Tanzania. It is linked with the Deaton and Paxson's (1998) paradox that, in most countries, the per capita demand for food decreases with household size. Deaton and Paxson (1998) argued that since larger households enjoy shared household public goods, they should have higher per capita consumption of private goods such as food, provided that they do not substitute too much toward the cheaper public goods. Yet, most studies show that both food demand and calorie consumption per capita decline with household size. Deaton and Paxson (1998) offered several possible explanations including that larger household have more economies of scale in food preparation, are better at eliminating wastage, and have higher food price elasticity. However, they state that among these explanations, "none holds out the promise of resolving the puzzle." A thorough investigation of why household calorie per capita decreases with household size is beyond the scope of this paper.

The female proportion, infant proportion and elderly proportion variables are significant and negative, indicating that households with higher percentages of females, infants and elderly people tend to consume lower calories per capita. This seems reasonable since holding all else constant, women typically require less energy than men, and children and elderly people need fewer calories than working-age adults.

Average women's schooling reduces calorie consumption. While the household head's schooling has a negative impact on calorie intake, the effect is insignificant, revealing that women's schooling may be more important than the head's schooling in making household nutrition decisions. It is possible that better-educated households tend to substitute away from basic calorie-rich foods (such as rice and other staples) to other characteristics such as quality and taste. Another reason could be that better-educated households are less likely to work in physically demanding, manual jobs, and therefore their energy requirements for everyday work are lower than those of less-educated households.

The coefficient on the urban variable is negative and significant, implying that households in rural areas consume more calories than those in the urban areas. There are at least three reasons for this. First, households in rural areas tend to consume a higher percentage of rice and other staple foods, which are rich in calories. In contrast, households in urban areas usually consume more diversified diets, with higher percentages of fruits, meats, fish and drink. Second, although household incomes in urban areas are higher than in rural areas, the price of food, and thus the price of calories, in rural areas is much lower than in urban areas. The average per capita expenditure of households in urban areas is about 1.8 times that of households in rural areas but the price of calories in urban areas is about double the price in rural areas. Lower prices per calorie in rural areas appear to have a positive effect on calorie consumption in those areas. Third, the urban population is less likely to work in physically demanding jobs than the rural population. The coefficient of farming variable is significant and positive, implying farming households tend to have higher calorie consumption than comparable non-farm households. One possible reason is that farming activities often require more calories than non-farm activities. Ethnic minority households tend to have higher calorie consumption than ethnic majority households. Perhaps it is because ethnic minority households tend to rely more on the traditional diets, which have a higher percentage of calorieefficient foods such as rice and other staple foods. 
Comparing the model with and without commune fixed effects; the addition of those commune fixed effects increases the R-square significantly, from 0.31 to 0.65 . However, the calorie elasticities in both models are very similar, implying the results are robust to unobservable community variables.

Turning to the food expenditure regressions, several remarks are in order. First, the impacts of factors such as household size, women's schooling, female head, ethnic minority, female proportion and farming have the same signs as in the calorie equation. Larger households, more educated women, households with a higher proportion of females, female-headed households, and ethnic majority households have lower food expenditure per capita than otherwise comparable households. On the other hand, farming households have higher food expenditure per capita than non-farming households.

Second, higher prices for pork, fish, fruit, other foods and FAFH lead to an increase in total food expenditure per capita. On the other hand, increases in the prices of poultry and drink lead to a decrease in total food expenditure per capita. This suggests that household food consumption patterns vary by different food categories. For most foods, the reduction in quantity does not compensate for the rise in prices, resulting in an increase in food expenditure per capita. For poultry and drink, however, households decrease their consumed quantity substantially, therefore their food expenditures per capita decline.

Third, some other significant factors should be noted. Other things equal, urban households have higher food expenditure than rural households but lower calorie consumption. This is as expected since food prices are much higher, but energy requirements are generally lower in urban areas than in rural areas. While the household head's age has a positive impact on calorie consumption, it has a negative impact on food expenditure. Accordingly, households with younger household heads tend to spend more on food but consume fewer calories than household with older heads. It is possible because young people appreciate food characteristics other than calorie content, such as taste, quality, and vitamin etc., more than older individuals.

The OLS results for calorie consumption assume zero correlation between per capita expenditure and the error terms. But this assumption may not hold, for several reasons. First, household income and therefore, expenditure could be constrained by nutrition, as efficiency wage theories suggest, resulting in a biased estimate of per capita expenditure in OLS due to endogeneity. Second, the OLS regressions may suffer from measurement error bias. Calorie consumption is calculated from household food consumption; therefore, any measurement error in household food consumption is transmitted into both calorie consumption and household expenditure data, leading to correlated measurement errors. Bouis and Haddard (1992) examined the issue and argued that the upward bias from correlated errors will generally outweigh the downward attenuation bias from the measurement error in expenditure data, resulting in a net upward bias. Subramanian and Deaton (1996) used non-food expenditure as an instrument and argued that the estimates from instrumental variable (IV) and OLS provide the lower bounds and the upper bounds of the true estimates.

In this study, three sets of instruments for PCE are used to overcome the possible problem of endogeneity and correlated measurement errors. The first specification (IV1) uses the logarithm of per capita non-food expenditure and its square. Non-food expenditure is a valid instrument if the measurement errors of non-food expenditure are assumed to be uncorrelated with measurement errors in food expenditure. It has been used by Subramanian and Deaton (1996), and by Gibson and Rozelle (2002), among others. The second set of instruments (IV2) is the logarithm of household per capita income and its square. Income is a valid instrument if calorie consumption does not affect household income. The data indicate that income should not, in general, be a constraint of calorie intake. It takes only 3 percent of household per capita income per day to buy 2,000 calories from rice per day for an average household. 
Even for an average household among the lowest-expenditure quintiles, it only takes about 6 percent of the household's per capita income per day to buy 2000 calories from rice. Therefore, per capita income could be a valid instrument. The third set (IV3) includes the logarithm of (estimated as the total value of fixed assets and durable goods) and its square. Measurement errors in non-food expense, income and wealth should be uncorrelated with measurement errors in food expenditure because these types of data were collected in different parts of the questionnaire.

The results from using IV regressions are presented in Table 5. The Durbin-Wu-Hausman test statistics imply that the OLS estimates may suffer from endogeneity bias. The signs and statistical significance of most variables are similar to the OLS estimates, except that children proportion variable has no impact on calorie consumption in the IV regressions.

Table 5: IV Regressions of Calorie Consumption Per Capita

\begin{tabular}{|c|c|c|c|c|c|c|}
\hline & \multicolumn{2}{|c|}{ IV1 } & \multicolumn{2}{|c|}{ IV2 } & \multicolumn{2}{|c|}{ IV3 } \\
\hline & Coef. & $\mathrm{z}$ & Coef. & $\mathrm{z}$ & Coef. & $\mathrm{z}$ \\
\hline Log of PCE & 0.97 & 8.41 & 1.22 & 8.39 & 1.90 & 5.12 \\
\hline Log of PCE squared & -0.04 & -6.45 & -0.06 & -6.62 & -0.10 & -4.59 \\
\hline \multicolumn{7}{|l|}{ Price of } \\
\hline Rice (log) & 0.03 & 2.21 & 0.02 & 1.92 & 0.03 & 2.56 \\
\hline Staples (log) & -0.04 & -7.50 & -0.05 & -7.58 & -0.04 & -7.14 \\
\hline Pork (log) & -0.13 & -7.65 & -0.14 & -8.21 & -0.12 & -6.68 \\
\hline Other meats (log) & -0.03 & -3.28 & -0.03 & -3.32 & -0.02 & -2.55 \\
\hline Poultry (log) & -0.02 & -3.69 & -0.02 & -3.48 & -0.02 & -3.68 \\
\hline Fish (log) & -0.03 & -4.17 & -0.03 & -4.58 & -0.02 & -2.67 \\
\hline Vegetables (log) & 0.01 & 0.85 & 0.01 & 0.88 & 0.00 & 0.6 \\
\hline Fruit (log) & -0.02 & -5.40 & -0.02 & -5.48 & -0.02 & -4.12 \\
\hline Other foods (log) & -0.01 & -2.91 & -0.02 & -3.31 & -0.01 & -1.85 \\
\hline Drink (log) & -0.04 & -6.84 & -0.04 & -7.23 & -0.03 & -6.29 \\
\hline FAFH (log) & 0.04 & 0.88 & 0.02 & 0.44 & 0.11 & 2.22 \\
\hline Head's age (log) & 0.01 & 0.39 & 0.00 & 0.14 & 0.01 & 0.58 \\
\hline Household size (log) & -0.14 & -16.99 & -0.13 & -16.38 & -0.14 & -17.2 \\
\hline Head's schooling (log) & -0.03 & -4.08 & -0.03 & -4.03 & -0.03 & -4.38 \\
\hline Women's schooling (log) & -0.01 & -1.33 & -0.01 & -2.15 & 0.00 & -0.68 \\
\hline Female head & -0.03 & -6.06 & -0.04 & -7.05 & -0.03 & -5.12 \\
\hline Urban & -0.03 & -4.41 & -0.04 & -4.56 & -0.02 & -2.92 \\
\hline Minority & 0.07 & 7.39 & 0.08 & 8.24 & 0.08 & 6.98 \\
\hline Infant proportion & -0.30 & -9.95 & -0.27 & -8.81 & -0.32 & -9.75 \\
\hline Children proportion & -0.01 & -0.69 & 0.01 & 0.40 & -0.03 & -1.5 \\
\hline Elderly proportion & -0.10 & -6.98 & -0.09 & -6.55 & -0.10 & -7.03 \\
\hline Female proportion & -0.04 & -2.75 & -0.03 & -2.49 & -0.04 & -2.78 \\
\hline Farming members & 0.04 & 17.50 & 0.04 & 18.12 & 0.04 & 16.4 \\
\hline Constant & 3.67 & 7.28 & 2.58 & 4.07 & -0.28 & -0.18 \\
\hline R-square & 0.31 & & 0.31 & & 0.29 & \\
\hline
\end{tabular}


Durbin-Wu-Hausman 7.44 9.37 31.90 test

Table 6 reports the expenditure elasticity of calories based on the OLS and IV results. The mean expenditure elasticity of calories is smaller for urban households and higher-income households than rural and lower-income households. The results from the model with commune fixed effects are slightly smaller than the model without these effects. The mean elasticity of calories is quite high for households in the bottom-income quintile, indicating that raising incomes of the poor may significantly reduce their nutritional deprivation.

Table 6 also shows that the mean expenditure elasticity of calories is much smaller than the mean expenditure elasticity of food ( 0.63 for OLS1 and 0.58 for OLS2). The difference reflects the shift from calorie-inexpensive foods such as rice and other cereals to more calorie-expensive foods. Thus, when income increases, households both increase calorie consumption and switch to higher quality, more calorie-expensive foods.

Table 6: Expenditure Elasticities of Calorie and Food Demand

\begin{tabular}{|c|c|c|c|c|c|c|c|}
\hline & \multicolumn{4}{|c|}{ Calorie elasticity } & & \multicolumn{2}{|c|}{$\begin{array}{c}\text { Food expenditure } \\
\text { elasticity }\end{array}$} \\
\hline & OLS 1 & OLS 2 & IV1 & IV2 & IV3 & OLS 1 & OLS 2 \\
\hline All & 0.24 & 0.22 & 0.24 & 0.27 & 0.23 & 0.63 & 0.58 \\
\hline Rural & 0.25 & 0.24 & 0.25 & 0.28 & 0.26 & 0.65 & 0.60 \\
\hline Urban & 0.20 & 0.17 & 0.19 & 0.21 & 0.14 & 0.58 & 0.51 \\
\hline Red River Delta & 0.23 & 0.21 & 0.23 & 0.26 & 0.21 & 0.62 & 0.56 \\
\hline North East & 0.25 & 0.23 & 0.25 & 0.28 & 0.26 & 0.65 & 0.60 \\
\hline North West & 0.28 & 0.27 & 0.28 & 0.33 & 0.33 & 0.69 & 0.65 \\
\hline North Central Coast & 0.26 & 0.24 & 0.25 & 0.29 & 0.27 & 0.65 & 0.60 \\
\hline South Central Coast & 0.24 & 0.22 & 0.23 & 0.26 & 0.22 & 0.63 & 0.57 \\
\hline Central Highlands & 0.25 & 0.23 & 0.25 & 0.28 & 0.25 & 0.64 & 0.59 \\
\hline South East & 0.22 & 0.19 & 0.21 & 0.23 & 0.16 & 0.59 & 0.53 \\
\hline Mekong River Delta & 0.24 & 0.21 & 0.23 & 0.26 & 0.22 & 0.62 & 0.57 \\
\hline Quintile 1 & 0.31 & 0.30 & 0.31 & 0.36 & 0.39 & 0.72 & 0.69 \\
\hline Quintile 2 & 0.27 & 0.25 & 0.27 & 0.31 & 0.30 & 0.67 & 0.62 \\
\hline Quintile 3 & 0.24 & 0.22 & 0.24 & 0.27 & 0.24 & 0.63 & 0.58 \\
\hline Quintile 4 & 0.22 & 0.19 & 0.21 & 0.23 & 0.17 & 0.60 & 0.53 \\
\hline Quintile 5 & 0.17 & 0.13 & 0.16 & 0.16 & 0.05 & 0.53 & 0.45 \\
\hline Non-poor & 0.23 & 0.20 & 0.23 & 0.25 & 0.21 & 0.61 & 0.55 \\
\hline Poor & 0.31 & 0.31 & 0.29 & 0.33 & 0.34 & 0.73 & 0.70 \\
\hline Ethnic majority & 0.23 & 0.21 & 0.21 & 0.29 & 0.21 & 0.62 & 0.56 \\
\hline
\end{tabular}




\begin{tabular}{llllll|ll} 
Ethnic minorities & 0.29 & 0.27 & 0.24 & 0.43 & 0.34 & 0.69 & 0.65 \\
\hline Non-farmer & 0.21 & 0.18 & 0.20 & 0.22 & 0.15 & 0.59 & 0.52 \\
Farmer & 0.25 & 0.23 & 0.25 & 0.28 & 0.26 & 0.65 & 0.60 \\
\hline Male-headed & 0.25 & 0.22 & 0.24 & 0.27 & 0.24 & 0.63 & 0.58 \\
Women-headed & 0.23 & 0.21 & 0.22 & 0.25 & 0.20 & 0.62 & 0.56 \\
\hline
\end{tabular}

The relationship between calories and income may be characterized by non-linear because, as their incomes increase, persons who are most undernourished may response more strongly than those who are better-nourished. To allow for that possibility, we also use nonparametric procedures to estimate the calorie-income relationship.

Figure 1 presents an unconditional kernel (non-parametric) regression of the logarithm of per capita calories on the logarithm of per capita expenditure. The figure shows increasing calorie consumption with household expenditure. The curve for rural households is higher than the curve for urban households, reflecting higher calorie consumption for rural households at similar levels of expenditure. This is not surprising because work in rural areas, particularly farm work, generally requires more energy than work in urban areas. The slopes of the curves indicate the expenditure elasticities of calorie consumption. The figure shows that calorie consumption rises steeply as expenditure increases at low level of expenditure and then flattens at higher expenditure levels. This implies a higher expenditure elasticity of calorie consumption for poorer households. The differences in slope are sharper in rural areas than in urban areas.

Figure 1: Kernel Regression of Calories on Expenditure (Bandwidth= 0.4)

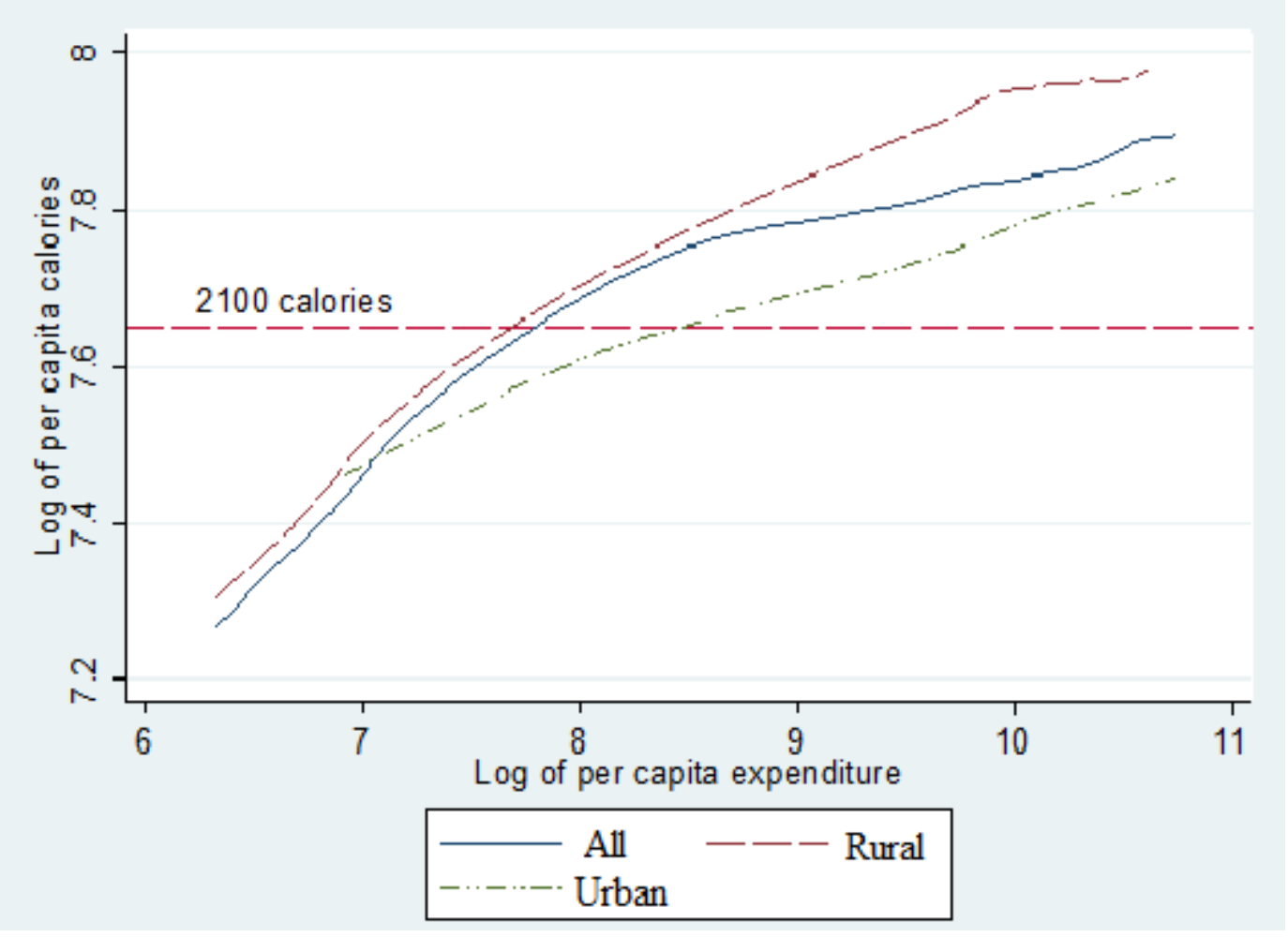


This non-parametric function is an estimate of the following equation:

$$
y_{i}=q\left(X_{i}\right)+\varepsilon_{i} \text { with } E\left(\varepsilon_{i} \mid X_{i}\right)=0
$$

in which $x_{i}, y_{i}$ are the per capita expenditure and the per capita calorie consumption, respectively, of household $i$. The functional form $q\left(x_{i}\right)$ is unknown and is estimated by kernel regression.

Figure 2 presents the non-parametric estimation of calorie elasticity, derived from the estimation in (5.4). Figure 2 indicates that for non-parametric procedure, the expenditure elasticity of calorie is lower as expenditure increases. The mean calorie elasticity is estimated at 0.20 . For the poorest quintile households, the calorie elasticities are in the range $0.15-0.3$. The calorie elasticities fall rapidly across expenditure levels. For the richest quintile, the calorie elasticities are estimated to be in the range from 0 to 0.05 for both non-parametric. Compared with the parametric estimates of calorie elasticities in Table 7, the non-parametric estimates are lower than the parametric estimates.

Figure 2: Nonparametric Estimates of Calorie Elasticity (bandwidth= 0.2)

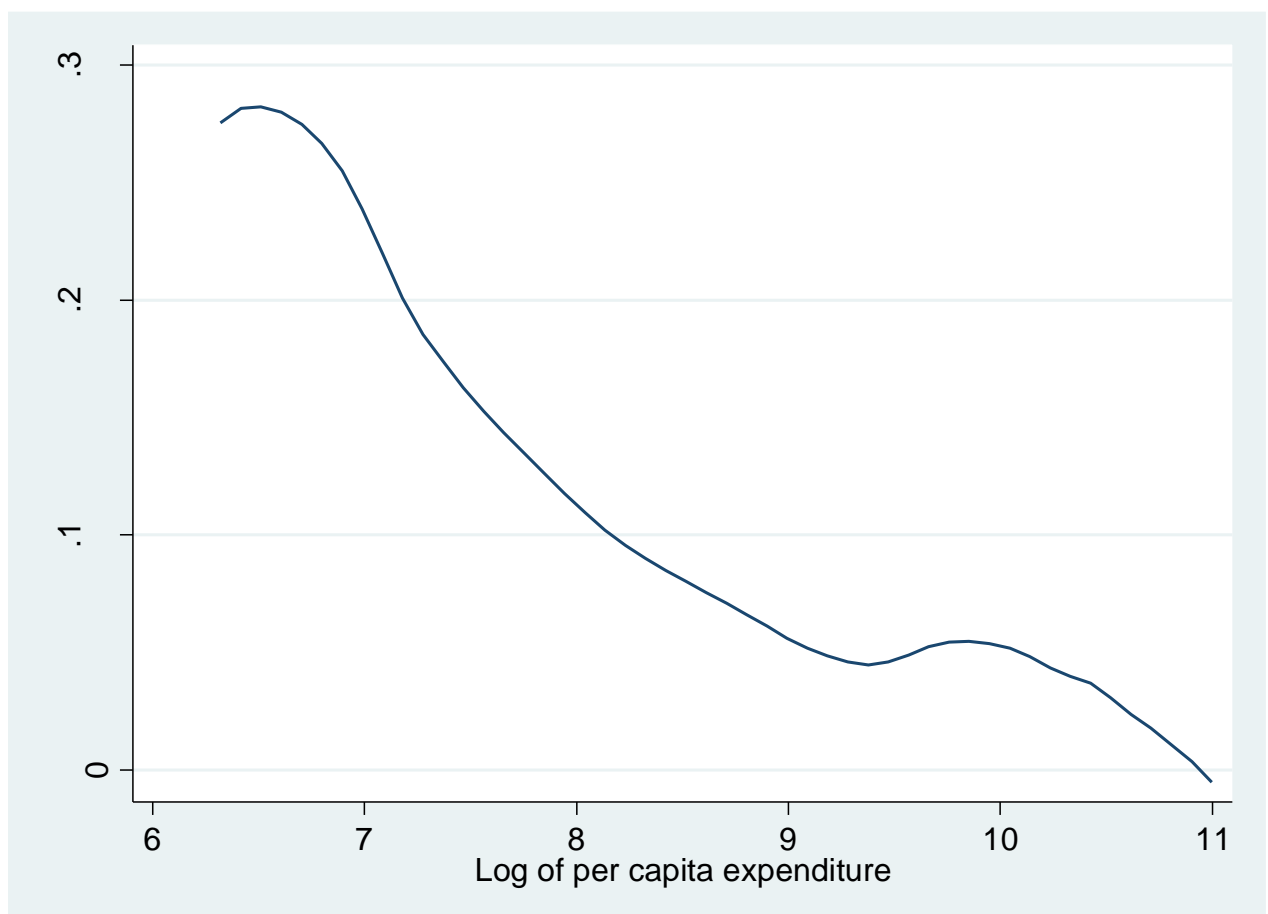

\section{Simulating the Effects of Income and Price Changes}

From the definitions of elasticity, one has the following equations

$$
\begin{aligned}
& \Delta C^{y}=C^{0} \frac{\varepsilon_{I} \Delta Y}{Y^{0}} \\
& \Delta C^{p}=C^{0} \frac{\varepsilon_{p i \Delta P_{i}}}{P_{i}^{0}}
\end{aligned}
$$

where $\Delta C^{y}$ is the change in calorie consumption due to real income (expenditure) change; $\Delta C^{p}$ is the change in calorie consumption due to food price change. 
From (5) and (6), one obtains the following equation, which is used to estimate the expected changes of calorie consumption from changes in both real incomes and commodity prices.

$$
\Delta C=C^{1}-C^{0}=C^{0} \frac{\varepsilon_{I} \Delta Y}{Y^{0}}+C^{0} \frac{\varepsilon_{p i} \Delta P_{i}}{P_{i}^{0}}
$$

where

$C^{0}, C^{1}$ : Calorie consumption at time 0 and at time 1 , respectively.

$\Delta Y$ : Change in per capita expenditure from time 0 to time 1.

$\Delta P_{i}$ : change in price of commodity $i$ from time 0 to time 1 .

$Y^{0}, P_{i}^{0}$ : level of per capita expenditure and price of commodity $i$ at time 0 , respectively.

$\varepsilon_{I}$ : Income elasticity of calorie consumption

$\varepsilon_{p i}$ : Price elasticity of calorie consumption with respects to commodity $i$.

Table 7 presents the results from six scenarios, using the results from normal OLS (without commune fixed effects) regressions, run separately for urban and rural areas*. The 2100 calories/day criterion is used as the calorie norm for determining undernutrition. The six scenarios are (1) income increases by 10 percent; (2) income increases by 50 percent; (3) prices of all food commodities increase by 10 percent; (4) prices of all food commodities increase by 50 percent; (5) price of rice increases by 10 percent and (6) price of rice increases by 50 percent. The assumption of a 50 percent increase in expenditure and food prices is fairly realistic. From 2003 to 2007, overall food prices and staple food (mostly rice) prices increased at the average rate of 10.9 percent and 11.5 percent annually, respectively. In 2008, there was a surge in the prices of food, in particular the price of rice. From January to September 2008 , food price increased by 33 percent, and food staples prices by 54 percent. With regards to income, GDP per capita in Vietnam increased by 64 percent during the period from 2002 to 2006 according to the World Bank's World Development Indicators.

A number of points are worth considering when examining Table 7. First, a 10 percent increase in real expenditure will reduce the headcount undernutrition index by about 3.3 percentage points (a 9 percent reduction), while a 50 percent increase will reduce the headcount undernutrition index by nearly 17 percentage points, from 38 percent to 21 percent (a 44 percent reduction). Expenditure increases lead to a faster reduction of undernutrition in rural areas than in urban areas, and in the poorest quintile than in the richest quintile. For example, a 50 percent increase in expenditure leads to a 48 percent reduction in headcount undernutrition in rural areas and a 34 percent reduction in urban areas; a 47 percent reduction among the poorest quintile, but only a 30 percent reduction among the richest quintile.

Second, when holding expenditure constant, food price increases lead to substantially higher levels of undernutrition. A hypothetical 10-percent increase in all food prices results in an 11-percent increase in the undernutrition headcount index (from 38 percent 42 percent), and a 50 -percent price increase raises the undernutrition headcount index by 56 percent (from 38 percent to 60 percent). Urban households and better-off households are more sensitive to increases in food prices. A 50-percent food price increase could raise the undernutrition index by 44 percent in rural areas, and by 87 percent in urban areas, by 28 percent among the poorest quintile, and by 100 percent among the richest quintile.

\footnotetext{
* Since there are few differences between the OLS and the IV estimates, I chose to use the OLS estimates in this subsection.
} 
Table 7: Impacts of Changes in Income and Prices on Undernutrition

\begin{tabular}{|c|c|c|c|c|}
\hline & $\begin{array}{l}\text { Headcount } \\
\text { index }\end{array}$ & $\begin{array}{c}\text { Nutrition } \\
\text { gap }\end{array}$ & $\begin{array}{l}\text { Headcount } \\
\text { index }\end{array}$ & $\begin{array}{c}\text { Nutrition } \\
\text { gap }\end{array}$ \\
\hline Scenarios & \multicolumn{2}{|c|}{ Increase by $10 \%$} & \multicolumn{2}{|c|}{ Increase by $50 \%$} \\
\hline \multicolumn{5}{|l|}{ Income increase } \\
\hline All & 34.8 & 5.4 & 21.4 & 3.0 \\
\hline Rural & 32.4 & 4.8 & 18.7 & 2.5 \\
\hline Urban & 41.9 & 7.1 & 29.5 & 4.6 \\
\hline Lowest quintile & 55.6 & 9.4 & 32.0 & 4.7 \\
\hline Highest quintile & 27.2 & 4.4 & 19.9 & 3.0 \\
\hline \multicolumn{5}{|c|}{ Food price increase } \\
\hline All & 42.3 & 7.2 & 59.6 & 12.7 \\
\hline Rural & 38.8 & 6.3 & 51.7 & 9.2 \\
\hline Urban & 53.0 & 10.0 & 83.4 & 22.9 \\
\hline Lowest quintile & 63.7 & 12.1 & 77.3 & 17.3 \\
\hline Highest quintile & 33.1 & 6.0 & 57.4 & 13.5 \\
\hline \multicolumn{5}{|l|}{ Rice price increase } \\
\hline All & 37.9 & 6.2 & 37.5 & 6.1 \\
\hline Rural & 35.5 & 5.6 & 33.6 & 5.2 \\
\hline Urban & 45.2 & 8.2 & 48.9 & 9.0 \\
\hline Lowest quintile & 60.1 & 10.9 & 58.0 & 10.4 \\
\hline Highest quintile & 29.0 & 4.9 & 30.3 & 5.3 \\
\hline \multicolumn{5}{|c|}{ Pork price increase } \\
\hline All & 40.0 & 6.7 & 48.4 & 8.5 \\
\hline Rural & 38.0 & 6.1 & 46.6 & 8.0 \\
\hline Urban & 46.2 & 8.4 & 53.6 & 10.2 \\
\hline Lowest quintile & 62.6 & 11.7 & 72.2 & 14.6 \\
\hline Highest quintile & 29.7 & 5.1 & 35.4 & 6.4 \\
\hline
\end{tabular}

Third, the impact of rice prices is more ambiguous than the impact of overall food prices. While an increase in all food prices harms both rural and urban areas, an increase in rice prices improves nutrition in rural areas while reducing nutrition in urban areas. A 10-percent rice price increase has almost no effect on the undernutrition index. Even a 50-percent rice price hike brings about a change of less than 2 percent of undernutrition index. However, the impact differs between urban and rural areas. A 50-percent rice price surge causes a reduction of undernutrition in rural areas by 7 percent, while raising it in urban areas by 10 percent. The impact of a 50-percent rice price increase is slightly beneficial to the lowest expenditure quintile (a reduction of 4 percent in undernutrition for a 50 percent price surge). Yet, even the richest quintile suffers an increase in its undernutrition rate of only 6 percent when the price of rice increases by 50 percent.

The reason for this minor impact of rice price changes on household nutrition is because the calorie elasticity with respect to the price of rice is small (-0.06 in urban areas and 0.03 in rural areas). Rice 
is the major traditional diet, consumed in almost every meal in Vietnam and providing about 60 percent of calorie consumption. Thus, dietary habits make rice demand rather inelastic, compared to some other foods. For example, the calorie elasticity with respect to pork price is -0.11 in urban areas, and -0.13 in rural areas. A 50-percent increase in the price of pork causes a 27 percent increase in undernutrition rate, 29 percent in rural areas and 20 percent in urban areas, 19 percent among the poorest quintile and 24 percent among the richest quintile.

The above analysis suggests that nutrition intakes of households in rural areas are more responsive to changes in expenditure than are households in urban areas. Likewise, the impacts of income changes are more significant for lower-income households than for higher-income households. On the other hand, urban and richer households are more responsive in lowering their calorie consumption when food prices increase than are rural and poorer households, respectively. These simulations show that both the magnitude and the distribution of income growth are important in reducing undernutrition in Vietnam. Encouragement of pro-poor growth would help significantly in reducing malnutrition since the poor people are more responsive to increasing their calorie consumption as their income increases. At the same time, household calorie consumption is highly responsive to food price changes. In fact, an increase of equal magnitude in both real expenditure and food prices results in a net negative effect on household nutrition. A 10-percent increase in both real expenditure and food prices raises the undernutrition rate by about 2 percent, while a 50-percent increase raises it by about 12 percent. Therefore, policies aimed at curbing food price inflation, particularly in the prices of pork, will help to improve household nutrition status.

\section{Conclusion}

This paper has presented a comprehensive analysis of calorie and micronutrient consumption in Vietnam using the 2006 household survey data from that country. The data suggest that food insecurity is a major problem. Nearly 40 percent of the population are not meeting their calorie requirements. In addition, dietary diversity is low, as nearly two-thirds of calories are from cereals, primarily rice. Employing parametric and non-parametric estimation techniques, the paper examines the relationship between household calorie consumption, per capita household expenditure, and food prices in Vietnam. The analysis indicates a positive and significant relationship between per capita expenditure and per capita calorie consumption. This is inconsistent with the view that income changes have little effect on nutrient intakes, as found in earlier studies such as Behrman and Wolfe (1984) and Bouis and Haddad (1992). The mean calorie elasticity is estimated at around $0.21-0.31$ by different parametric methods and 0.20 by a non-parametric method. The finding of a positive and statistically significant calorie elasticity implies that income growth can alleviate undernutrition, although its impact on undernutrition is much less than its impact on poverty. Lower-expenditure groups have relatively higher calorie elasticities in all models. Therefore, economic growth that is pro-poor will help to reduce undernutrition more effectively than a proportional increase of income by all groups. In a simulation, undernutrition is found to be very responsive to changes in income and in food prices. For example, a 10 percent increase in income reduces the undernutrition head count index in Vietnam by 9 percent.

Note that when income increases, households tend to replace cheap sources of calories for more expensive ones. As a result, the price of calories increases when income increases. This suggests that a household not only increases its calorie consumption with rising income, but also tends to buy more expensive foods, which have higher quality, better taste and/or higher quantity of micronutrients.

The impact of food prices on calorie consumption is negative and significant for most food items. The estimates imply that a 10 percent increase in all food prices would increase the undernutrition head 
count index by 11 percent. This suggests that lower food prices would increase calorie intakes. The remarkable exception is the price of rice, which has a positive net impact on calorie consumption. Rising rice prices have negative effects on the real income of many households, particularly urban consumers. However, higher rice prices also have positive impacts on farmers' income, resulting in increased calorie consumption in rural areas.

This finding has important policy implications regarding the link between food prices and nutrition in Vietnam. Overall, this result implies that policies that raise income will considerably improve calorie consumption in Vietnam, particularly among poor households. Therefore, pro-poor growth and targeted measures toward poor households are important for improving the nutrition status of Vietnamese households. At the same time, curbing food price inflation is necessary to preserve the achievements in nutrition from recent economic growth in Vietnam. Yet, while overall food price increases can lead to substantial worsening in the households' nutritional situation, an increase in the price of rice price has very little effect on undernutrition prevalence, due to the "income effect". Many developing country governments use price control on staple foods to guarantee food and nutrition security. In Vietnam, the government uses price and export controls for rice with the view to preserve food security. My results indicate that an increase in rice price, in contrast, leads to higher calorie and micronutrient consumption, and has no negative impacts on the average household nutritional status. It even results in a slight reduction of the undernutrition prevalence rate among the poor households.

Conflicts of Interest: The authors declare no conflict of interest.

\section{References}

Abdulai, A., Aubert, D. (2004), Nonparametric and parametric analysis of calorie consumption in Tanzania. Food Policy 29 (2), 113-129

Arimond, M., Ruel, M. T., 2004. Dietary diversity is associated with child nutritional status: evidence from 11 demographic and health surveys. Journal of Nutrition 134, 2579-2585.

Baulch, B., Masset, E., 2003. Do monetary and non-monetary indicators tell the same story about chronic poverty? a study of Vietnam in the 1990s. World Development 31 (3), 441-453.

Behrman, J., Deolalikar, A., 1987. Will developing country nutrition improve with income? a case study for rural South India. Journal of Political Economy 95 (3), 492-507.

Behrman, J., Wolfe, B., 1984. More evidence on nutrition demand: still income seems overrated and women's schooling underemphasized. Journal of Development Economics 14 (1-2), 105-128.

Bouis, H. E., Haddad, L. J., 1992. Are estimates of calorie- income elasticities too high? a recalibration of the plausible range. Journal of Development Economics 39, 333-364.

Dawson, P. J., Tiffin, R., 1998. Estimating the demand for calories in India. American Journal of Agricultural Economics 80, 474-481.

Deaton, A, and C Paxson. 1998. Economies of Scale, Household Size, and the Demand for Food. Journal of Political Economy 106 (5): 897-930.

Foster, J. , J. Greer, Thorbecke, E., 1984. A class of decomposable poverty indices. Econometrica 52, 761-766. 
Gibson, John \& Kim, Bonggeun, 2013. Quality, Quantity, and Nutritional Impacts of Rice Price Changes in Vietnam. World Development 43(C), 329-340.

Hoddinott, J., Yohannes, Y., 2002. Dietary diversity as a food security indicator. Discussion papers 136, International Food Policy Research Institute (IFPRI).

Leibenstein, H., 1957. Economic Backwardness and Economic Growth. Wiley, New York.

Mirrlees, J., 1975. A pure theory of underdeveloped countries. In Reynolds. L. (Ed.). Agriculture in Development Theory. Yale University Press, New Haven.

Minot, N., Baulch, B., 2005. Spatial patterns of poverty in Vietnam and their implications for policy. Food Policy 30(5-6), 461-475.

Mishra, V., Ray, R., 2006. Dietary diversity, food security and undernourishment: the Vietnamese evidence. Mimeo. University of Tasmania, Australia.

Molini, V., 2006. Food security in Vietnam during the 1990s: the empirical evidence. UNU-WIDER Research Paper 2006/67, Helsinki.

National Institute of Nutrition, 1995. Food Products in Vietnam, Composition and Nutritive Value. Medicine Publisher, Hanoi, Vietnam.

Pitt, M. (1983), Food Preferences and Nutrition in Rural Bangladesh. Review of Economics and Statistics 65(1), 105-14

Ravallion, M., 1990. Income effects on undernutrition. Economic Development and Cultural Change 38, 489515.

Ray, R., 2007. Dietary changes, calorie intake and undernourishment: a comparative study of India and Vietnam. Discussion Paper 2007-01. School of Economics and Finance, University of Tasmania, Australia.

Sahn, D., 1988. The effect of price and income changes on food-energy intake in Sri Lanka. Economic Development and Cultural Change 36 (2), 315-340.

Skoufias, E., 2003. Is the calorie-income elasticity sensitive to price changes? evidence from Indonesia. World Development 31(7), 1291-1307.

Stiglitz, J., 1976. The efficiency wage hypothesis, surplus labor, and the distribution of income in L.D.C.s. Oxford Economic Papers 28, 185-207.

Subramanian, S., Deaton, A., 1996. The demand for food and calories. Journal of Political Economy 104, 133162.

Trinh Thi, Huong \& Simioni, Michel \& Thomas-Agnan, Christine, 2018. Decomposition of changes in the consumption of macronutrients in Vietnam between 2004 and 2014. Economics \& Human Biology 31(C), 259-275.

$\mathrm{Vu}$, Linh \& Glewwe, Paul, 2011. Impacts of Rising Food Prices on Poverty and Welfare in Vietnam. Journal of Agricultural and Resource Economics 36(1), pages 1-14.

World Bank (2012) Well begun, not yet done -Vietnam's remarkable progress on poverty reduction and the emerging challenges. Washington DC ; World Bank. 